\title{
Da Experiência Discente à Formação Docente em Educação a Distância
}

\author{
From Student Experience to Teacher Education in Distance Education
}

\section{Adriana Ripka ${ }^{1}$}

${ }^{1}$ Universidade Tecnológica Federal do Paraná, UTFPR 


\title{
Resumo
}

Este trabalho tem como objetivo analisar dois cursos ofertados na modalidade a distância, cursados pela autora, para relatar a experiência vivida como discente e a contribuição desta experiência para a formação docente em educação a distância. A partir da literatura sobre o tema, foram selecionados alguns elementos que serviram de base para a análise comparativa entre os cursos, tais como: tecnologias utilizadas, conteúdo, tutoria, autonomia do aluno, interação professoraluno, interação aluno-aluno e avaliação on-line. Como resultado, é importante destacar que, principalmente, as dificuldades encontradas como discente, no decorrer de um curso, podem impactar positivamente na elaboração de uma disciplina/ curso. Ao se antecipar aos possíveis obstáculos, que possam ser encontrados na construção de uma disciplina/curso, ampliase a possibilidade de se compartilhar o conhecimento de forma mais eficaz. Outro ponto relevante é que o conhecimento da teoria, sobre mecanismos que podem fortalecer a iteração entre professor-aluno e aluno-aluno, não é suficiente para garantir que esta ocorra, sendo necessário um esforço constante por parte do docente em educação a distância para que os estímulos à interação obtenham sucesso.

Palavras-chave: experiência discente, formação docente, educação a distância

\begin{abstract}
This work aims to analyze two courses offered, in the distance modality, taken by the author of this study, to report the experience lived as a student and the contribution of this experience to the teacher education in distance education. From the literature on the topic, some elements were selected that served as a basis for comparative analysis between courses, such as: technologies used, content, tutoring, student autonomy, teacher-student interaction, student-student interaction and on-line assessment. As a result, it is important to highlight that mainly the difficulties encountered as a student during a course can positively influence the development of a discipline / course. By anticipating possible obstacles that may be encountered in the construction of a discipline / course, the possibility of sharing knowledge more effectively is expanded. Another relevant point is that the knowledge of the theory, about mechanisms that can strengthen the interaction between teacher and student and student and student is not enough to guarantee that it occurs, being necessary a constant effort on the part of the teacher in distance education so that the stimuli to interaction are successful.
\end{abstract}

Keywords: student experience, teacher training, distance education 
A evolução da tecnologia da comunicação e informação (TIC) tem se mostrado cada vez mais presente no cotidiano da sociedade atual, e isso se deve ao desenvolvimento da internet, que possibilitou novas formas de comunicação e de transmissão de informação. Por exemplo, vídeos, fóruns, hipertextos, e-mails e outras formas de tecnologia e ferramentas que podem contribuir no contexto educacional, como apresentado em Gomes (2016).

A possibilidade de utilizar ferramentas síncronas (cuja comunicação entre os atores se realiza ao mesmo tempo) e assíncronas (cuja comunicação pode ser feita em tempos diferentes) permite que em um ambiente virtual, compartilhado por pessoas de diferentes localidades, haja interação, ou seja, que duas pessoas ou mais possam compartilhar informações e experiências e que possam contribuir para o aprendizado uma das outras. Como definição de virtual podemos considerar Lévy (1996, p. 15), que afirma que o "virtual tende a atualizar-se, sem ter passado, no entanto, à concretização efetiva ou formal".

Ao se estudar os conteúdos relacionados às TICs, aos AVAs, aos cursos de Educação a Distância (EAD), ao construtivismo na educação e outros temas similares, se chegou à seguinte pergunta norteadora: A experiência obtida como discentes, em um curso ofertado na modalidade a distância, contribui na formação de docentes na EAD?

Para tentar responder esta pergunta a presente autora apresenta uma reflexão, a partir dos conteúdos pertinentes ao tema, educação a distância, sobre a própria experiência como discente em dois cursos na modalidade a distância curso EAD 1 e curso EAD 2.

Assim, se tem como objetivo geral analisar dois cursos ofertados, na modalidade a distância, cursados pela autora, para relatar a experiência vivida como discente e a contribuição desta para a formação docente em educação a distância. Para tanto, alguns objetivos específicos precisaram ser atendidos, como: identificar quais elementos de cada curso se mostram de acordo com a literatura sobre educação a distância; relatar a identificação de elementos que poderiam melhorar a experiência como discente; e identificar pontos de complementariedade, ou de similaridade, entre os cursos.

Além da presente introdução, este relatório está dividido em mais quatro seções, apresentadas na sequência: Educação e ensino a distância, contendo o referencial teórico que embasa o desenvolvimento do relatório; Métodos e técnicas de pesquisa, no qual são apresentados os passos seguidos para a comparação dos cursos analisados; Relato da experiência e resultados da comparação dos cursos; e por fim, as considerações finais.

\section{Educação e Ensino a Distância}

Educação e ensino a distância envolvem a forma mais atual de compartilhamento de conhecimento, que exige habilidades dos docentes para transformar as plataformas virtuais em salas de aulas atrativas para os discentes, que se dispõem a estudar de acordo com suas disponibilidades de horários pessoais, muitas vezes limitadas, conciliando com horários de trabalho, ou mesmo, com estudos em cursos presenciais.

Sobre os conteúdos disponibilizados em ambiente virtual de aprendizagem (AVA), a forma de exposição destes e os estímulos do docente aos discentes para a interatividade, relação entre o aluno e o computador por exemplo, são pontos que exigem estudo e aplicação de métodos que viabilizem que um curso a distância obtenha 
sucesso. Neste caso, se assume sucesso como a transmissão do conhecimento por parte do docente e a recepção e compreensão deste conteúdo por parte do discente.

Nesta seção são abordados, brevemente, três núcleos conceituais: 1) Conceituação de educação a distância (EAD) e ambiente virtual de aprendizagem (AVA); 2) Construtivismo na educação; e 3) Semiótica e metodologia de ensino. Estes núcleos têm como função servir de suporte teórico para a reflexão a ser feita sobre os cursos a serem analisados, assim, destacando elementos que podem ser observados e comparados entre os cursos.

\section{Conceituação de Educação a Distância (EAD) e Ambiente Virtual de Aprendizagem (AVA)}

Como passo inicial, é importante que se entenda o que é a chamada educação a distância (EAD). Para Moran (2002, p. 1) a "educação a distância é o processo de ensino-aprendizagem, mediado por tecnologias, onde professores e alunos estão separados espacial e/ou temporalmente". Trata-se de uma forma que evolui à medida que se façam avanços nas tecnologias de comunicação e que estas sejam incorporadas às formas de ensino.

As tecnologias da informação e comunicação (TICs), o ambiente virtual de aprendizagem (AVA) e a possibilidade de interação, por exemplo, são elementos que, em se tratando de ensino, são passiveis de diferentes percepções e compreensões de utilização, dependendo da visão que cada autor tem sobre o assunto. Sobre isso pode-se elencar algumas visões pedagógicas da tecnologia aplicada à educação, como as discutidas em Silva (2017), como as tendências liberais; tendência liberal tradicional; tendência liberal renovada progressista, tendência liberal renovada não-diretiva; tendência liberal tecnicista; tendências pedagógicas progressistas; tendência progressista libertadora; tendência progressista libertária; e tendência crítico-social dos conteúdos. Cada uma destas tendências traz consigo uma interpretação do papel do professor, do aluno e das ferramentas tecnológicas que influenciam na forma como se vai refletir sobre a forma de aprendizagem.

Sobre a formação de um docente na educação a distância, pode-se resgatar uma citação de Gomes (2016, p. 40), na qual afirma que "Kant entende que o que faz a ligação entre a experiência, frente aos fenômenos, e nossas conclusões é a crítica", para refletir que a crítica pode ser um elemento que auxilie na formação docente. Pode-se interpretar que a análise da experiência desta autora ao longo da participação dos dois cursos a distância, ao se valer de criticidade, pode trazer entendimento e, consequentemente, proporcionar maior capacidade de relacionar elementos contribuintes com a aprendizagem na elaboração de cursos futuros, ou seja, influenciando na formação docente.

Para Haidt (1995, p. 144), os procedimentos de ensino devem:“[...] contribuir para que o aluno mobilize seus esquemas operatórios de pensamento e participe ativamente das experiências de aprendizagem, observando, lendo, escrevendo, experimentando, propondo hipóteses, solucionando problemas, comparando, classificando, ordenando, analisando, sintetizando etc".

Para se alcançar tal amadurecimento nas escolhas de tais procedimento, pode-se cogitar o "caminho inverso" para a formação do docente, ou seja, como discente este pode analisar de forma crítica o curso ao qual participou, para em sua atuação futura como docente tenha entendimento dos elementos que julga passiveis 
de reprodução e de substituição, ou mesmo, chegar à circunstância de elaborar procedimentos que julga mais alinhados ao curso.

Gomes e Moreira (2016, p. 71) afirmam, ainda, que é "importante ressaltar que os saberes dos professores são combinações entre o fazer e o agir, entre a realidade individual e social, entre a cognição e emoção [...], é nas experiências diárias que também se constroem os saberes". Diante do exposto nesta seção, o desenvolvimento do presente relatório de experiência se justifica tanto pela contribuição para a formação da presente autora quanto para o compartilhamento de experiência com leitores interessados pelo tema. Reforçando um ponto levantado por Mill (2016, p. 445), de que "as publicações sobre a temática fomentam as práticas de gestão, docência, aprendizagem e incorporação de tecnologias no processo educacional".

Sobre as nomenclaturas relacionadas ao ambiente virtual de aprendizagem (AVA) e sua definição, Schlemmer e Fagundes (2000) destacam que:

Ambientes Virtuais de Aprendizagem (Virtual Learning Environments-VLE), Ambientes de Aprendizagem Online, Sistemas Gerenciadores de Educação a Distância, Software de Aprendizagem Colaborativa são denominações utilizadas para softwares desenvolvidos para o gerenciamento da aprendizagem via Web. São sistemas que sintetizam a funcionalidade de software para comunicação mediada por computador (CMC) e métodos de entrega de material de cursos online (p. 4).

Assim, o AVA pode ser considerado como o software ou plataforma onde o docente disponibiliza o conteúdo do curso e recursos de aprendizagem e os discentes podem usufruir desta estrutura em prol do conhecimento. Pode-se ainda, assumir a definição de Munhoz (2011, p. 21), a qual assume que os Ambientes Virtuais são "locais onde proliferam informações educacionais e orientações de estudo que possibilitam às pessoas com capacidade para a aprendizagem independente condições de aprender".

\section{Construtivismo na Educação}

A perspectiva construtivista sobre a educação a distância permite uma mudança na forma de se compreender a tecnologia, abandonando a visão determinista de que esta é neutra (não possui influência da sociedade) e apenas gera impactos no usuário, ou seja, passa a se compreender que a tecnologia é socialmente construída e, assim de ter sua criação e seu uso conforme a interação pessoa-objeto (Feenberg, 2010).

Transferindo a ideia de construtivismo para a elaboração de cursos a distância, torna-se relevante a compreensão dos elementos que devem ser observados na construção de um curso, ou seja, o conhecimento teórico de fatores que possam viabilizar uma melhor compreensão de um conteúdo por parte dos diferentes tipos de alunos e o conhecimento prático, seja de cursos anteriores ou de estudos de caso que apontam vantagens, ou desvantagens, na adoção de diferentes métodos.

Numa percepção construtivista, Haidt (1995, p. 22) afirma que a "criança deve adquirir o saber pela experiência e pela experimentação própria. O papel da escola não é comunicar o saber pronto e acabado, mas ensinar as crianças a adquiri-lo, quando Ihes for necessário". Tal afirmação pode ser transferida à formação do docente, se considerar que a este não se aplica a ideia de fornecer um "conhecimento pronto" e sim estimular a 
pesquisa e sua capacidade de relacionar assuntos e experiências, para que possa aplicar no ensino de seus futuros alunos.

Ainda nesta teoria, Machado e Mirada (2006, p. 10) destacam ainda que "o erro não deve ser considerado como o oposto do certo, que é valorizado como verdadeiro ou bom, tampouco deve ser tratado com complacência ou rigor", nesta visão o erro deve ser tratado como um elemento contributivo para o aprendizado, podendo ser relacionada a percepção de Haidt (1995). Pode-se ainda relacionar à visão de Piaget (1983 como citado em AXT, 2000, p. 57) “[...] não se faz de acordo com uma progressão ou marcha linear, mas avançando patamar por patamar com a necessidade de reconstruções em cada novo patamar alcançado".

\section{Semiótica e Metodologia de Ensino}

A semiótica trata do conteúdo a ser disponibilizado e a forma como é disponibilizado ou, como indicada por Santaella (2004), pode ser considerada como a ciência que estuda os signos em geral atribuída a formas de linguagem e à comunicação. São elementos básicos que fazem parte da semiótica: os sinais; sintomas; ícones; índices; símbolos e nomes que são conceituados por Fidalgo e Gradim (2005):

1. Sinais são signos que desencadeiam mecânica ou convencionalmente uma ação por parte do receptor.

Os sinais de rádio e de televisão, por exemplo, provocam nos respectivos receptores determinados efeitos. Mas também há uma aplicação convencional dos sinais, como nos casos de "dar o sinal de partida", "fazerIhe sinal para vir", "dar o sinal de ataque". Este tipo de signos é utilizado em máquinas, e é utilizado por homens e animais.

2. Sintomas são signos compulsivos, não arbitrários, em que o significante está associado ao significado por um laço natural. Um síndroma é uma configuração de sintomas. Assim, a febre é um sintoma de doença, tal como a geada noturna é um sintoma de que a temperatura atmosférica desceu até zero graus centígrados. 3. Ícones são signos em que existe uma semelhança topológica entre o significante e o significado. Uma pintura, uma fotografia são ícones na medida em que possuem uma semelhança com o objeto pintado ou fotografado. Subtipos de ícones são as imagens, os diagramas e as metáforas. Os diagramas, como os planos de uma casa, têm uma correspondência topológica com o seu objeto. As metáforas têm uma semelhança estrutural, de modo que é possível fazer uma transposição de propriedades do significante para o significado.

4. Índices são signos em que o significante é contíguo ao significado. Um tipo importante de índices são os deícticos, as expressões que referem demonstrativamente, como "este aqui", "esse aí", "aquele ali". Os números nas fardas dos soldados são índices, assim como um relógio também é um índice do tempo. 5. Símbolos são signos em que, não havendo uma relação de semelhança ou de contiguidade, há uma relação convencional entre representante e representado. Os emblemas, as insígnias, os estigmas são símbolos. A relação simbólica é intencional, isto é, o simbolizado é uma classe de objetos definida por propriedades idênticas. 
6. Os nomes são signos convencionais que designam uma classe extencional de objetos. Enquanto os signos que designam intencionalmente o fazem mediante uma propriedade comum do objeto, os indivíduos que se chamam "Joaquim" apenas têm em comum o nome. Aqui não há um atributo intencional que os caracterize (p. 20-21).

Conhecer os elementos básicos da semiótica, como os conceitos apresentados por Fidalgo e Gradim (2005), pode auxiliar em um outro tema, aqui relacionado, e de importância para o compartilhamento e conhecimento, a didática e metodologia de ensino.

Para a escolha de uma metodologia, a ser utilizada na construção de uma disciplina/curso há a necessidade de um amplo conhecimento por parte do docente, por exemplo, das teorias existentes sobre o assunto. Não só conhecimento teórico, mas também saber aplicá-las de forma a favorecer a compreensão do conteúdo, exigindo do docente estar em constante atualização. Para Zabalza (2004, p. 113) "a profissionalização docente refere-se aos alunos e ao modo como podemos agir para que aprendam, de fato, o que pretendemos ensinar-lhes".

As diferentes atuações docentes podem ser guiadas, por exemplo, por eixos epistemológicos, como: Racionalismo; Empirismo; e Interacionismo. Bem como por diferentes possibilidades de metodologia de ensino, como: Aulas expositivas; Estudo dirigidos; Uso de jogos; e Trabalhos em grupo - que podem utilizar Técnica de painel; Técnica de seminário; Brainstorming; Simpósio; Discussão 66 ou Phillips 66; Grupos de cochicho; Estudo de Casos; Estudo do meio; Método da descoberta; Método de solução de problemas; ou Métodos de projetos.

Do trabalho em grupo, que é um elemento de discussão neste relatório, Munhoz (2011, p. 82) destaca que há uma capacidade de "desenvolver e melhorar habilidades individuais para o uso do conhecimento, aceitar responsabilidade pelo aprendizado individual e do grupo, e desenvolver a capacidade de refletir são algumas das vantagens que podem ser auferidas pelo trabalho em grupo".

\section{Métodos e Técnicas de Pesquisas}

A construção do presente relatório se apoia na experiência vivida pela autora ao participar como discente em dois cursos a distância, identificados ao longo do relatório como Curso EAD 1 e Curso EAD 2. Tal nomenclatura foi escolhida para que não seja atribuído mérito, ou demérito, a um ou a outro curso, durante a leitura do texto. Desta forma, pretende-se estimular uma análise crítica sobre as informações presentes neste relatório que, sob a luz da literatura e a visão da autora sobre estas, pode-se destacar o que se mostrou eficiente do ponto de vista discente para sua formação como docente.

Como técnica, utilizada na presente pesquisa, destaca-se a análise qualitativa que, de acordo com Bardin (2011, p. 145-146), refere-se a um processo intuitivo, maleável e adaptável que não está "amarrado" a repetições de eventos, como em análises quantitativas, mas propicia a "elaboração das deduções específicas sobre um acontecimento ou uma variável de inferência precisa" (Bardin, 2011, p. 145).

Para a elaboração do referencial teórico e seleção dos elementos a serem analisados, na comparação entre os cursos, optou-se pelo método de categorização de Bardin (2011), para qual foram pesquisados artigos em 
bases de periódicos como o Periódico Capes, Scopus e Scielo, visando enriquecer a discussão teórica que embasa a presente discussão.

Como elementos de análise na comparação entre os cursos, foram selecionados: tecnologias utilizadas, conteúdo, tutoria, autonomia do aluno, interação professor-aluno, interação aluno-aluno, avaliação on-line.

Na próxima seção, é apresentada a caracterização dos cursos EAD 1 e EAD 2 e a experiência vivida pela autora em cada um.

\section{Relato da Experiência e Resultados da Comparação dos Cursos}

A autora teve a possibilidade de cursar o EAD 1 e o EAD 2 em dois momentos diferentes e com a decisão que levou a iniciar os cursos também diferentes. O EAD 1 foi um curso iniciado com a primeira-intensão de se adquirir um título na área de possível atuação, enquanto que o EAD 2 foi iniciado com a intensão de busca de conhecimento e melhoria na qualificação para uma futura atuação como docente.

Ambos os cursos são reconhecidos pelo Ministério da Educação (MEC) e possuem um quadro de docentes/ tutores com currículos compatíveis com a formação oferecida, verificados pela plataforma Lattes (http://lattes. cnpq.br/). Este é um dos pontos que permite que se faça a presente comparação, que seguirá divididas em subseções. A primeira referente à apresentação do curso EAD 1, a segunda referente a apresentação do curso EAD 2 e a terceira referente aos resultados da comparação.

\section{Curso EAD 1}

O curso EAD 1 trata-se de um curso de pós-graduação Lato Sensu, em nível de especialização, em área específica da Administração e com carga horária de 420 horas. Ao longo do curso foram ofertadas doze (12) disciplinas, mais a disciplina de Trabalho de Conclusão de Curso.

As disciplinas ofertadas foram: Ambientação, Gestão de negócios; Gestão de Marketing; Gestão de estratégia competitiva e negociação; Gestão de finanças, Mercado Financeiro e de Capitais; Planejamento Estratégico; Direito empresarial; Logística da Cadeia de Suprimentos; Gestão da Produção - Bens e Serviços; Gestão de pessoas; Ética e sustentabilidade; Metodologia e Trabalho de Conclusão de Curso.

A primeira disciplina, Ambientação, permite que o aluno se familiarize com o AVA do curso que, com o apoio do professor responsável pela disciplina, inicia a utilização das ferramentas disponíveis, realizando pequenas atividades semanais obrigatórias que passam a fazer parte das demandas das disciplinas seguintes.

Na Figura 1 é possível verificar as tecnologias disponíveis no AVA do Curso EAD 1, que juntamente com a descrição da avaliação on-line pode-se verificar a frequência com que as ferramentas são utilizadas.

Figura 1

Características Curso EAD 1

\begin{tabular}{ll}
\hline Elementos de análise & Curso EAD 1 \\
\hline Tecnologias utilizadas & Plataforma on-line, com espaço para disponibilização de conteúdo de texto, links para \\
conteúdo complementar como vídeos do YouTube, espaço para mensagem entre \\
professor-aluno e aluno-aluno, fórum e espaço para avaliação individual.
\end{tabular}




\begin{tabular}{|c|c|}
\hline Elementos de análise & Curso EAD 1 \\
\hline Conteúdo & $\begin{array}{l}\text { De qualidade e direcionado ao objetivo do curso, com referências reconhecidas na área. } \\
\text { Formato: Textos, links para sites externos e vídeos complementares na plataforma YouTube. }\end{array}$ \\
\hline Tutoria & $\begin{array}{l}\text { Um professor responsável por cada disciplina, sendo o mesmo responsável pelas dúvidas } \\
\text { sobre o conteúdo disponibilizado. }\end{array}$ \\
\hline Autonomia do aluno & $\begin{array}{l}\text { Liberdade de acesso ao conteúdo, no horário de interesse do aluno. Interação obrigatória } \\
\text { com os demais alunos, devido a trabalhos em grupo. Obrigatório, no mínimo, um acesso } \\
\text { semanal devido a atividades no fórum. }\end{array}$ \\
\hline Interação professor-aluno & $\begin{array}{l}\text { Interação semanal do professor com os alunos através de atividades no fórum e sua correção. } \\
\text { Disponibilidade para contato individual com o aluno através da ferramenta de mensagens. }\end{array}$ \\
\hline Interação aluno-aluno & $\begin{array}{l}\text { Interação semanal nas atividades do fórum, esporádica em pelo menos uma atividade em } \\
\text { dupla ou grupos, por disciplina, e contato aberto entre os alunos através do espaço } \\
\text { disponibilizado a mensagens individuais. }\end{array}$ \\
\hline Avaliação on-line & $\begin{array}{l}\text { - participação semanal nas atividades do fórum. } \\
\text { - atividade avaliativa em dupla ou grupos. } \\
\text { - atividade individual diversificada, abrangendo respostas de questionários, construção de } \\
\quad \text { textos, resenhas, etc. }\end{array}$ \\
\hline
\end{tabular}

Nota: Elaborado pelo autor (2016).

O estabelecimento claro do professor responsável por cada disciplina permite que dúvidas sobre temas específicos, durante a elaboração do TCC, sejam direcionadas pelo aluno direto ao professor da disciplina específica. O domínio do conteúdo foi percebido tanto na seleção do conteúdo quanto nas respostas aos questionamentos, o que oferece confiabilidade ao curso.

A autonomia do aluno é limitada pela obrigatoriedade de acesso semanal, contudo, os horários de acesso se mantiveram flexíveis, ou seja, o aluno possui flexibilidade para conciliar o curso com outras atividades, como emprego ou cursos presenciais.

A interação professor-aluno se mantém frequente ao longo de cada disciplina em decorrência das atividades semanais, que além da postagem das atividades em fórum ocorre por comentários sobre acertos e erros, identificados, sobre o conteúdo. A opção mensagem no AVA permite a interação individual do aluno com o professor, e vice-versa, para dúvidas específicas.

A interação aluno-aluno, devido à atividade semanal em fórum e trabalhos em duplas ou grupos, permite a troca de experiências, trabalho colaborativo e, até mesmo, contato interpessoal possibilitando apoio entre os alunos e estímulo à continuidade das atividades. Tal interação pode ser considerada próxima à interação em um curso presencial.

A avaliação on-line do curso EAD 1 se baseia em atividades semanais, atividades em dupla ou em grupos e atividade individual diversificada. O conjunto de avaliação, estimula a frequência no ambiente on-line e o fortalecimento da interação professor-aluno e aluno-aluno. 


\section{Curso EAD 2}

O curso EAD 2 trata-se de um curso de pós-graduação Lato Sensu, em nível de especialização, em área específica da Educação e com carga horária de 450 horas. Ao longo do curso foram ofertadas nove (9) disciplinas, mais a disciplina de Trabalho de Conclusão de Curso.

As disciplinas ofertadas foram: Produção e Roteirização on-line; Ambiente Virtual de Aprendizagem; Semiótica; Didática e Metodologia no Ensino; Tecnologia e Educação; Design de Curso; Design de material didático; Hipermídia e Multimídia; Orientação de Trabalho de Conclusão de Curso - TCC e Trabalho de Conclusão de Curso TCC.

Na Figura 2 é possível verificar as tecnologias disponibilizadas no AVA do curso EAD 2, as quais permitem o acesso ao conteúdo e a interação professor-aluno e aluno professor. As disciplinas possuem, desde a primeira disponibilizada, excelente conteúdo, com grau de profundidade que permite que os alunos que concluam o curso tenham conhecimento suficiente para atuar na área de educação a distância.

A disponibilidade de vídeo-aulas no AVA, baseadas no conteúdo disponibilizado em texto, permite que os alunos possam optar pela forma de apresentação de conteúdo que for mais adequada a sua melhor forma de aprendizagem. Contudo, a disponibilidade de fórum e de espaço para mensagem não se mostrou proveitosa com relação à interação aluno-aluno. Uma possibilidade para isso pode ser a não visualização dos integrantes da turma, ou seja, os alunos que estão cursando a disciplina ao mesmo tempo.

Figura 2

Características Curso EAD 2

\begin{tabular}{ll}
\hline Elementos de análise & Curso EAD 2 \\
\hline Tecnologias utilizadas & Plataforma on-line, com espaço para disponibilização de conteúdo de texto, links para \\
& conteúdo complementar como vídeos do YouTube, vídeo-aulas, espaço para mensagem, \\
fórum e espaço para avaliação individual.
\end{tabular}

Conteúdo

De qualidade e direcionado ao objetivo do curso, com referências reconhecidas na área.

Formato: Textos, vídeo-aulas, links para sites externos e vídeos complementares na plataforma YouTube.

Tutoria

Autonomia do aluno

Interação professor-aluno

Interação aluno-aluno
Um tutor, sem delimitação de forma clara sobre a extensão das disciplinas as quais é responsável, e um professor responsável por dúvidas sobre o conteúdo específicos.

Liberdade de acesso ao conteúdo, no horário de interesse do aluno. Sem interação obrigatória, com os demais alunos. Obrigatório, no mínimo, um acesso mensal devido à avaliação online individual.

Interação do professor com os alunos através e-mails e mensagens informativas.

Disponibilidade para a contato individual com o aluno através da ferramenta tutoria.

Acesso a chat de "tira-dúvidas" em horários específicos. Palestras on-line.

Possibilidade de interação, não obrigatória através do fórum. 


\begin{tabular}{ll}
\hline Elementos de análise & Curso EAD 2 \\
\hline Avaliação on-line & Duas avaliações mensais: uma com questões objetivas e outra com uma questão dissertativa, \\
englobando: elaboração de textos, respostas a questões e atividades relacionadas à \\
formação docente.
\end{tabular}

Nota: Autoria própria (2016).

Sobre a autonomia do aluno, este tem a obrigatoriedade de acessar a disciplina, pelo menos, uma vez ao mês, devido às atividades obrigatórias de avaliação on-line. Esta apresentada em dois formatos: um questionário objetivo e uma atividade dissertativa. Apesar de desaconselhável o acesso único ao conteúdo, o que pode prejudicar a compreensão do conteúdo disponibilizado, não há uma obrigatoriedade de que o acesso seja frequente.

A interação professor-aluno pode ser feita de forma eficiente pelo fórum, tutoria, em palestras on-line ou em chat "tira-dúvida" em horário específico. O espaço destinado a mensagens se mostrou como um canal apenas receptivo de mensagens gerais, por parte do professor/tutor aos alunos, pois, não são apresentadas opções de destinatários.

A interação aluno-aluno se mostrou deficitária, pois a ausência de atividades em duplas ou em grupos não estimula tal interação e a não disponibilidade de uma forma de visualizar a turma, ou seja, os alunos que estão cursando a disciplina ao mesmo tempo, faz com que não se tenha um contato individualizado com outros alunos. Uma possibilidade interação é a publicação aberta no fórum, contudo, sem um direcionamento o número de alunos que usufruem desta ferramenta é reduzido.

As duas avaliações on-line, obrigatórias, abrangem satisfatoriamente o conteúdo disponibilizado. Toma-se aqui como satisfatório o fato de que o aluno necessita acessar o conteúdo para conseguir concluir as avaliações, ou seja, é improvável o alcance da nota mínima sem a compreensão do conteúdo disponibilizado.

\section{Análise Comparativa}

Como discente, as observações da presente autora com relação aos cursos EAD poderiam se restringir ao que foi, ou não, do seu agrado, das preferências por um ou outro tipo de avaliação ou interação. Com a perspectiva de possível aplicação, como docente, dos conteúdos aprendidos no curso, voltado à educação, a percepção passa a ser ditada pelos elementos existentes na teoria e se foi possível presenciar o funcionamento, ou não, destes elementos ao longo de um curso EAD.

A mediação da tecnologia no processo de ensino-aprendizagem, citado por Moran (2002), no item 2.1, é vivenciada ao longo dos dois cursos, no AVA de ambas, cabendo destaque às vídeo-aulas disponibilizadas no curso EAD 2, que alcançam alunos que possuem um melhor aprendizado a partir de recursos audiovisuais, e ao campo mensagem do curso EAD 1 que permite maior interação aluno-aluno.

Os dois cursos, EAD 1 e EAD 2, se mostraram com qualidade de conteúdo, demonstrando a dedicação dos docentes para com a construção da disciplina, demonstrando conhecimentos da semiótica e de diferentes 
metodologias para diferentes formas de aprendizagens, como os citados por Fidalgo e Gradim (2005) e Santaella (2004), apresentados no item 2.3.

No entanto, a disponibilidade de ferramentas no AVA não é condição decisiva para que estas sejam utilizadas por todos os alunos da mesma forma. Neste caso o apontamento de Zabalza (2004), no item 2.3, sobre a profissionalização do docente foi corroborado, pois, a atuação dos docentes é que permitiu o estímulo ao uso mais intensivo de uma ou outra ferramenta. Por exemplo, no curso EAD 1 a ferramenta fórum ganha destaque na utilização pelo professo e alunos, devido a atividades, na no curso EAD 2 o contato via ferramenta tutoria é destacado como link professor-aluno.

Como discente, se observa que a interação aluno-aluno, vivenciada no curso EAD 1 foi mais proveitosa, em termos de troca de experiências e suporte para continuidade do curso, do que no curso EAD 2. Isso pode ter ocorrido, possivelmente, pelo fato de que, como apontado por Munhoz (2011), com o trabalho em grupo é possível desenvolver a capacidade de refletir sobre questões de pontos de vista diferentes, não se restringindo ao aluno isolado e ao professor.

Neste sentido, a frequência de avaliação on-line no curso EAD 1 e o trabalho em dupla, ou grupo, estimulam uma maior interação aluno-aluno e consequentemente professor-aluno, dado que pontos de vista diferentes sobre um mesmo conteúdo propiciam dúvidas que, em geral, buscam um consenso no contato dos alunos com o professor.

No curso EAD 2, a disponibilidade de palestras on-line, sobre temas específicos, e os chats voltados para sanar dúvidas, em horários específicos, se mostrou como um espaço rico para o compartilhamento de conhecimento. Contudo, a falta de familiaridade com os demais alunos pode reduzir a interação, ou até anular, em casos de alunos com características mais introspectivas, pois pode-se ter a sensação de "primeira aula" a cada evento.

Da presente experiência como discente, nos cursos EAD 1 e EAD 2, aliada ao conhecimento adquirido no curso voltado para a educação, a presente autora pôde adquirir conhecimento de possível aplicação na posição de docente em EAD. Em concordância com o Feenberg (2010), Machado e Mirada (2006), Haidt (1995) e Piaget (1983), sobre a abordagem construtivista, se pode afirmar que a experiência discente contribui para a formação docente em EAD.

No entanto, vale destacar que o conhecimento da teoria não garante o conhecimento de aplicação dos recursos disponíveis para a construção de uma disciplina em um AVA. A aplicação e experimentação das ferramentas e teorias é que levam a uma melhor formação. Neste caso, os erros e acertos vivenciados em curso EAD, na posição de discente, permite que se possa projetar passos mais "seguros" (apesar de não garantidos) em termos de escolha de conteúdo, forma de avaliação e de interação no desenvolvimento de uma disciplina/curso. 


\section{Considerações Finais}

Ao longo do relatório foi possível verificar, brevemente, alguns conceitos base sobre educação a distância $(E A D)$, ambiente virtual de aprendizagem (AVA), construtivismo na educação, semiótica e metodologia de ensino que veio a contribuir na análise comparativa entre dois cursos, EAD 1 e EAD 2.

Com relação à metodologia, a partir da análise de conteúdo dos artigos utilizados no referencial teórico foi obtido elementos para comparação entre os dois cursos analisados, sendo estes elementos: tecnologias utilizadas, conteúdo, tutoria, autonomia do aluno, interação professor-aluno, interação aluno-aluno e avaliação on-line.

Dada a intenção da presente autora em não se atribuir mérito ou demérito a nenhum dos dois cursos analisados, foram levantados pontos, identificados por esta como contribuindo mais ou menos com o compartilhamento de conhecimento. A partir disso, se chegou a uma resposta positiva à pergunta inicial: Se a experiência obtida como discentes, em um curso ofertado na modalidade a distância, contribui na formação de docentes na EAD?

Assim, se considera como atendido o objetivo geral proposto para o presente relato, pois, se observou que a experiência como discente contribuí para a formação docente em educação a distância, principalmente pela possibilidade de se projetar escolhas entre ferramentas e metodologias experimentadas ao longo dos cursos. Outro ponto a ser destacado, dentro dos resultados obtidos, é que alguns modelos podem levar a uma sala virtual com grande interação aluno-aluno e professor-aluno, similar a um curso presencial, mas sem as limitações de dia e hora, ou podem levar a uma sala virtual vazia, na qual ecoam os pensamentos de um único aluno, sobre o conteúdo disponibilizado, que conta apenas com a voz do professor/tutor para guia-lo. 


\section{Referências}

AXT, M. (2000). Tecnologia na educação, tecnologia para a educação: um texto em construção. Informática na educação - teoria \& prática, Recuperado em 13 janeiro, 2017, de http://www.seer.ufrgs.br/ InfEducTeoriaPratica/article/view/6392

Bardin, L. (2011). Análise de conteúdo. Lisboa: Edições 70.

Feenberg, A. (2010). Do essencialismo ao construtivismo: a filosofia da tecnologia em uma encruzilhada. In: Neder, R. T. (org.) A teoria crítica de Andrew Feenberg: racionalização democrática, poder e tecnologia (pp.205 251), Brasília: Observatório do Movimento pela Tecnologia Social na América Latina / CDS / UnB / Capes.

Fidalgo, A. \& Gradim, A. (2005). Manual de semiótica. Universidade Beira Interior, Portugal. Recuperado em 20 fevereiro, 2017, de www.bocc.ubi.pt/pag/fidalgo-antonio-manual-semiotica 2005.pdf

Gomes, C. A. S. (2016). Guia de Estudo - Tecnologia e Educação. Minas Gerais: UNIS/MG.

Gomes, C. A. S. \& Moreira, A. M. (2016). Guia de Estudo - Ambiente Virtual de Aprendizagem. Minas Gerais: UNIS/ MG.

Haidt, R. C. C. (1995). Curso de Didática Geral. São Paulo: Ática.

Lévy, Pierre. (1996). O que é o virtual? São Paulo: Ed. 34.

Machado, F. B. \& Miranda, L. L. (2006). O uso do construtivismo e da afetividade nas metodologias de ensino a distância. Rio de Janeiro: Puc-Rio.

Mill, D. (2016). Educação a Distância: cenários, dilemas e perspectivas. Revista de Educação Pública, 25(59/2), 432454.

Moran, J. M. (2002). O que é educação a distância. São Paulo.

Munhoz, A. S. (2011). O estudo em ambiente virtual de aprendizagem: um guia prático. Curitiba: Ibpex.

Santaella, L. (2004). Comunicação e semiótica. São Paulo: Hacker Editores.

Silva, D. B. (2017). As principais tendências pedagógicas na prática escolar brasileira e seus pressupostos de aprendizagem. Recuperado em 15 janeiro, 2017, de http://www.ufsm.br/lec/01_00/DelcioL\&C3.htm.

Schlemmer, E., \& Fagundes, L. C. (2000). Uma Proposta Para Avaliação De Ambientes Virtuais De Aprendizagem Na Sociedade Em Rede. PGIE-UFRGS, Porto Alegre. Recuperado em 10 abril, 2017, de http:// orientacoestccpeadprofdoris.pbworks.com/f/Projetos+de+Aprendizagem__Léa+Fagundes.doc.

Zabalza, M. A. (2004). O ensino universitário - seu cenário e seus protagonistas. Porto Alegre: Artmed. 